\title{
11
}

\section{The practical realities of policy on the run: A practitioner's response to academic policy frameworks}

Louise Gilding

Policy on the run is an oxymoron. It is a given that policy based on robust qualitative and quantitative evidence is more likely to succeed. It is also a given that gathering and analysing evidence requires time and resources. However, the reality is that policy developers no longer have the luxury of time and resources. Decision-makers want answers to complex problems: fast. How can robust policy be delivered with limited time and resources?

The following is a practical reflection of my 20-plus years of experience in developing and leading strategy and policy across a wide array of governmental portfolios. It discusses how I made sense of many policy models, and how I iteratively developed my own blended approach based on four questions and a triangle.

My approach is by no means a perfect model, but is a reflection on how I have reconciled the constraints of time and resources with a desire to deliver policies that make a difference for my community. I will outline my approach by covering the following topics:

- my working definition of policy

- communicating policy to effect change 
- a blended approach: four questions and a triangle

- what is the problem?

- what does the evidence tell us?

- listening for evidence

- multidisciplinary teams

- what should we do?

- what does success look like?

I then offer an example of applying the four questions and a triangle approach, in the form of a case study drawn from the experience of being involved as the executive group manager Housing ACT in developing the ACT housing strategy: Growing and renewing public housing 2019-2024 (Housing ACT 2019).

\section{My working definition of policy}

'Policy is rather like the elephant-you recognise it when you see it but cannot easily define it' (Cunningham 1963). Working in the ACT Government is my vocation. My purpose is to serve my community. My mission is to solve problems by developing policies and systems that help solve people's issues and make this city a better place. What I have seen is that the essence of strategy and policy development is solving problems.

Good policy makes a difference for people. People intuitively recognise solutions to their problems, and when they hear a government policy that sounds right, it resonates. A further characteristic of good policy is that it requires minimal regulation because its design encourages buy-in and incentivises behavioural change. Often, when it is the right thing to do, policy is self-enforcing and does not actually need to be highly regulated. There are many different policy interventions such as 'tools, instruments, methods, measures, and interventions to change the behaviour of individuals and groups' (Freiberg 2010, p. 82). As a policymaker, it is my task to understand how these interventions can be used to achieve more or less of a certain (desired or un-desired) behaviour. To express this in economic terms, policy interventions should decrease negative externalities or increase positive externalities. In summary, my definition of policy is solving people's problems by incentivising different individual and community behaviours so that this city is a better place to live and work. 


\section{Communicating policy to effect change}

One of the things I regularly say to my policy team-and this is perhaps a provocative statement-is that policy that cannot be implemented is not actually policy because it cannot effect change. Often policies sit in the bottom drawer, not being implemented because they are so complicated that even the experts cannot explain them. As Albert Einstein stated: 'If you can't explain it simply, you don't understand it well enough' (Goalcast 2017).

When I finished my Australia and New Zealand School of Government (ANZSOG) masters, my head was laden with policy models, frameworks and triangles. Asked to present my work on public sector transformation to key decision-makers, I wrote a short, high-level 'pitch'. At the end of the discussion, the following comment was made: 'This is great. Just don't let the policy wonks get hold of it'. Sage advice for any senior public servant-don't let the policy wonks get hold of it. Interestingly, that is precisely what I am: a policy wonk!

\section{A blended approach}

My response is 'yes, of course'. But the words have had great impact. As complicated as a problem or an issue may be, my job is to understand the complexity and to communicate it with simplicity so that decisionmakers can actually effect change. Scott and Baehler (2010, p. 35) put it this way: 'High performing public officials succeed in balancing these competing imperatives on a daily basis in their professional practice ... developing various integrated and blended models". There are many ways to develop policy and numerous policy models: intervention logic, policy cycle, eight-fold path of policy analysis, the rational and participatory approaches, the panic loop, cost-benefit analysis, multi-criteria analysis, systems mapping economic modelling and forecasting, scenario analysis and others. Present these models and the majority of decision-makers' eyes glaze over. Ignore them and risk throwing the 'baby out with the bathwater'. Equally, over-privileging a particular or favoured model reduces or limits options. By bringing together my academic study and the practical reality of working with time-poor decision-makers, I developed my own 'blended approach'. It is an amalgamated, flexible method. Importantly, when under pressure, I can remember it. When confused 
by multiple presenting problems, drowning in data, swamped with unrealistic recommendations and flailing for direction, it provides me with a way to stay on track and deliver results. In short it is four questions and a triangle.

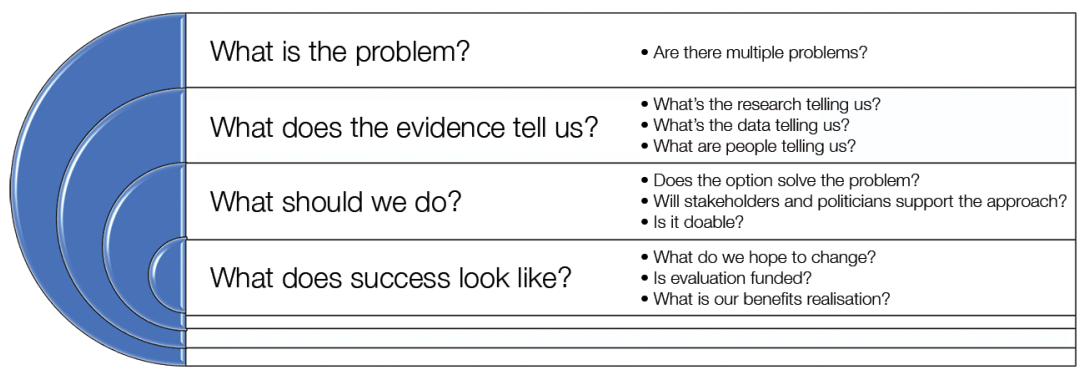

Figure 11.1. The four questions.

\section{Question 1: What is the problem?}

There might be multiple problems or sub-problems. Problem definition is an iterative process. As literature reviews, environmental scans and desktop analysis are commenced, the problem or problems to be solved are illuminated. There are many problem definition frameworks that can be employed at this point such as intervention logic and triple bottom line analysis. In my experience, it is worthwhile spending as much time as possible to understand, and revisit throughout policy development, this fundamental question. In his book The regulatory craft, Malcolm Sparrow (2000, pp. 137-54) implores readers to 'pick important problems and fix them'. It is tempting to move ahead to solutions without a thorough problem definition. However, one of the greatest and obvious policy pitfalls is to be working on a solution to the wrong problem.

\section{Question 2: What does the evidence tell us?}

Sources of evidence can generally be arranged into three main groups:

- research and literature

- qualitative data

- quantitative data. 
There are many frameworks that can be employed to collect and analyse evidence, but 'fitness for purpose acts as the main criterion for determining what counts as good evidence' (Nutley 2009, p. 5); in other words, what suits the available time, resources and scope of the problem. Time spent answering Question 1 (what is the problem?) helps to clarify the evidence collection and analysis task required.

For many years I have used the Triple bottom line assessment for the ACT Government (ACT Government 2012a) as a framework to quality assure problem definition and identify evidence requirements by answering a series of questions about potential environmental, economic and social impacts. Within the framework, there is a multidimensional scan against which a proposal can be assessed. While often used at the back end of policy development, using the scan up-front provides a mechanism to identify what evidence is needed. When operating in time critical situations, the scan can provide a solid ready reckoner, particularly in relation to what evidence is known and unknown.

In January 2019, the ACT Government announced that it would establish a wellbeing index to monitor economic progress and guide its budget allocations (Burgess 2019). A first for an Australian jurisdiction, the index, which follows on from New Zealand's wellbeing budget, will monitor a range of indicators including homelessness rates and housing affordability, health outcomes, gender parity, environmental sustainability, social capital and participation in community activities. These indicators will no doubt drive evidence requirements for policy teams. A spokesperson for the ACT Government explained that: 'Drawing them together as a set of indicators that are regularly monitored and reported against will see them play a greater role in driving how we design and deliver both policy and service delivery' (Burgess 2019).

Good policy needs good evidence-qualitative and quantitative. What are the numbers telling us? What are people telling us? Do the numbers and people tell a consistent story? Stakeholder engagement is fundamental to good policy, and I am passionate about listening intently to what people are telling us. What are people's stories? Who are we actually listening to? Who do we actually need to ask? Engagement with people is key. There are so many different ways we can engage, and with the advent of social media and technology, these techniques are evolving and providing new opportunities for evidence collection. 


\section{Listening for evidence}

There is much insight to be gained from actually (and deeply) listening to people and hearing the threads of the different things they say and the wisdom and insight that each individual brings. I find that it is from these conversations that recommendations start to form. These conversations can also triangulate the other evidence: literature, research and data.

By listening with clean (i.e. without bias) intent, I often hear people reflect in their own words what the theories, data and research says. For example, when engaging with stakeholders to develop Growth, diversification and jobs: A business development strategy for the ACT (ACT Government 2012b), I would often hear: 'there's not enough money to commercialise my idea', reflecting classic market failure. Academics express it like this:

This more active government role is justified by the identification of market failures that hamper innovation. The existence of market failure is one of the principal rationales for government regulation. Suboptimal innovation occurs when market mechanisms are unable to yield socially optimal levels of investment in innovation either because the market is not getting or seeing the right signals or there are bans to diffusion and adoption. By its very nature innovation is steeped in risk. Only a small number of entrepreneurs succeed. Nevertheless, the successes more than compensate for the failures along the way. Indeed, in the innovation process the failures are just as important. Without investor willingness to experiment and risk their capital and the capital of others, there would be no innovation process. The role of government is to actively support this process by countering the market failures that describe innovation investment. (De Rassenfosse 2011)

In short, lack of investment makes it difficult to bring an idea to market. That is all a time-poor decision-maker has to hear. But that short statement needs a foundation of literature, research and data. One of the roles of a policy team is to be 'clean' (without bias) translators of evidence.

When consulting outside government, I find it is best to drop the rhetoric. Stakeholders need the genuine you-not the political spin and not the rhetoric of academics. Methodology matters less than building genuine rapport with stakeholders. It is important to hear the quiet voices. The squeaky stakeholders get attention but, for me, it is the unobtrusive voices, without hidden agendas, that can often articulate the underlying problems and potential solutions better than anyone else. 
Strong stakeholder relationships are imperative, particularly when operating on the run. Stakeholder relationships formed in times of relative calm are lifelines in times of policy crisis. On many occasions, I have called a trusted community representative to test and triangulate what I am hearing and what the operational data is showing. I want to know what people are actually experiencing, and why. Keeping in touch and having a finger on the pulse is a given for any policy officer wanting to provide up-to-date intelligence and evidence to decision-makers.

Finally, a word about frontline workers (both internal to government and external): they are critical yet often overlooked stakeholders. Without frontline input and know-how, policy implementation will most likely fail. Listening and engaging with frontline workers and ensuring their perspective is part of the evidence base and used to inform program design is akin to 'insuring' for success.

\section{Multidisciplinary teams}

'Innovation happens at the cross-section of disciplines' (Gilding 2018). If we are to find solutions to complex problems such as homelessness, we need input from a broad range of disciplines and experts. Typically, policy teams within the public sector and in academic and research institutions only attract people from within their portfolio area. Justice departments have lawyers, planning department have planners and human services departments have social workers. For many years, I have intentionally built multidisciplinary teams bringing together lawyers, economists, planners, social workers, psychologists and behavioural economists. I deliberately bring different expertise, training and thinking into one division with the aim of sparking innovative thinking.

A word of warning: multidisciplinary teams are harder to manage. A cross-section of disciplines brings a cross-section of personalities, thinking styles, communications styles and cultural belief systems that can be difficult to coordinate. Nonetheless, the rewards of building such teams are great, as they deliver creative responses to policy problems. Moreover, and in my experience, multidisciplinary teams tend to have higher rates of successful implementation. 


\section{Question 3: What should we do?}

A natural human tendency is to jump straight from the problem to the solution. However, successful solutions are found in understanding the problem and analysing the evidence. From these first two questions, the potential answers to the third become evident. Once possible options are established, I often use Moore's (1995) 'strategic triangle' as a criteria to judge options and establish a preferred recommendation. It sets out three broad tests (Alford \& O'Flynn 2009) for any public sector strategy:

1. Does the option create public value (i.e. does it solve the problem)?

2. Is the option aligned with the authorising environment (i.e. will politicians and stakeholders support the approach)?

3. Are the operational capabilities available (i.e. is it doable)?

Options that meet these tests are preferred.

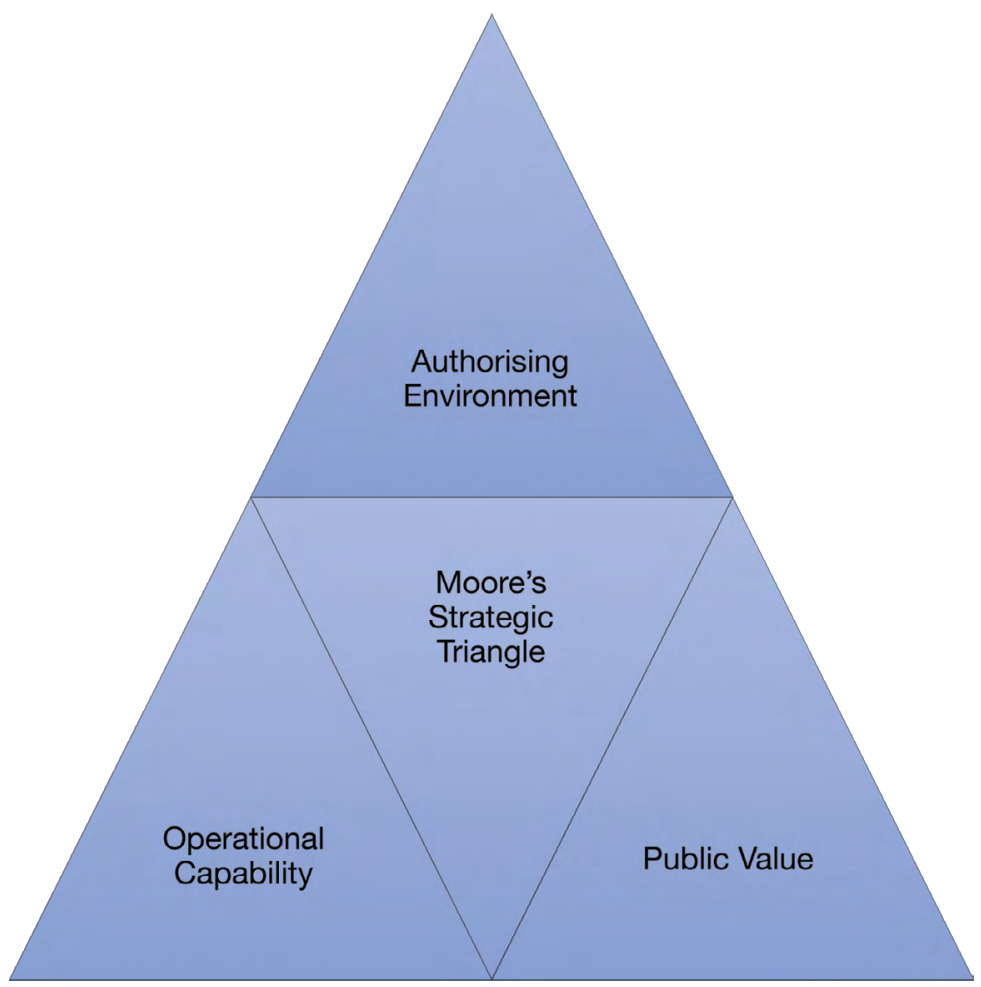

Figure 11.2. Moore's strategic triangle.

Source: Author's diagram based on Moore (1995). 
The strategic triangle concept has caused disagreement between public managers and academics: 'Moore has noted that one aim of the Kennedy project ${ }^{1}$ was to make sense of what is was that managers actually did; not what academics thought they did' (Alford \& O'Flynn 2009, p. 175). Regardless of Moore's motivation, reflecting on my policy successes and failures, there is a correlation with whether the triangle is aligned or misaligned.

The following two examples illustrate my point:

- At the ACT level of government, an attempt by one minister to legislate for note acceptors on poker machines without a cash input limit was reversed by her own government, as it failed to provide for harm minimisation (Westcott 2015). This shows a clear misalignment between public value and the authorising environment.

- At the federal level of government, the Commonwealth's Home Insulation Program was misaligned in terms of operational capability: industry did not have the capacity to deliver the required volume and regulatory requirements were insufficient to ensure safe installation.

It is an illuminating exercise to review policy failures in relation to what part of the triangle was misaligned.

\section{Question 4: What does success look like?}

Rather than as an afterthought, the determinants of success need to be identified as part of policy development. Funding for evaluation is now commonly accepted and, more frequently, demanded. Understanding what the policy is designed to change and establishing benchmarks and data collection to measure success is essential and accepted as good practice.

\footnotetext{
1 The Kennedy project brings together 15 years of Moore's research, observations and teaching about what public sector executives should do to improve the performance of public enterprises.
} 


\section{Case study: ACT housing strategy: Growing and renewing public housing 2019-2024²}

A recent Productivity Commission (2017) inquiry into human services declared that 'the social housing system is broken'. There is no doubt that public housing in Australia faces many challenges. In 2017, the ACT Government committed to developing a housing strategy to address housing affordability across all tenures and income ranges. My Housing ACT policy team was responsible for work in relation to homelessness and public housing. The policy and strategy development took over two and a half years. We used my four questions and triangle approach as a broad guide that integrated other tools and approaches to deliver the Growing and renewing public housing 2019-2024 plan (Housing ACT 2019). The elements under each stage are described below.

\section{Question 1: What's the problem?}

After many months of discussion and data analysis, the multiple problems facing the public housing enterprise were synthesised into several key issues, including that:

- a growing population and increasing demand for affordable housing without corresponding property supply means growing waiting times

- an ageing property portfolio means that houses are increasingly expensive to maintain and expensive for tenants to heat and cool

- there is a mismatch between current stock and what tenants actually need (this is seen in high underutilisation rates [people are in houses that are too big for them] and overcrowding [people are in houses that are too small] and many tenants want a transfer)

- public housing provides sub-market rent, which means the portfolio, while asset rich, does not have the cash flow to address the three issues above unless it uses capital for ongoing costs.

2 I would like to acknowledge the various policy officers and experts who contributed tirelessly to developing the Growing and renewing public housing plan, a genius team who delivered an outcome that will make a significant difference for vulnerable people in Canberra. 


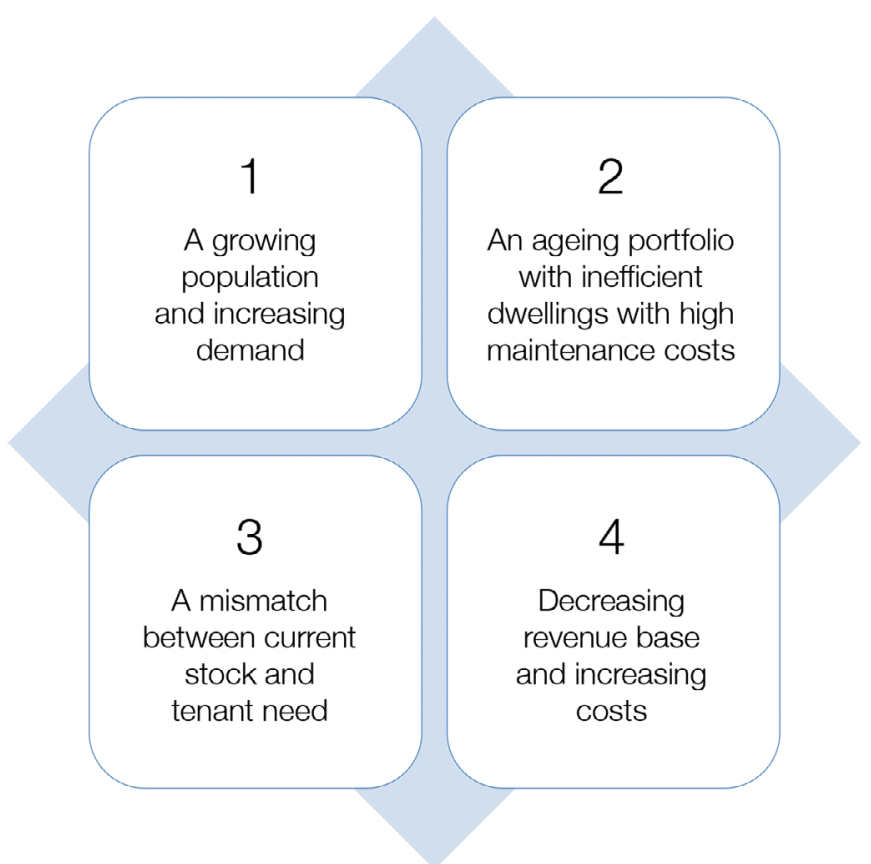

Figure 11.3. What is the problem?

\section{Question 2: What does the evidence say?}

An extensive evidence base was compiled as part of developing the housing strategy that included careful consideration of the key influences on the ACT housing market. This key land and economic data is outlined in the ACT housing strategy (ACT Environment, Planning and Sustainable Development Directorate [EPSDD] 2018), and showed that households in income quintiles 3-5 have a crowding-out impact on incomes $1-2$, placing the latter in housing stress - that is, the lowest 40 per cent of income earners are spending more than 30 per cent of their incomes on housing. Translated from 'policy wonk', this means that, 'on average, the ACT is Australia's most affordable jurisdiction to buy and second most affordable for renting ... but there's no doubt that there are people on low incomes and facing disadvantage who remain left behind in the current housing market' (EPSDD 2018, p. 1).

A substantial evidence base was developed that included reviewing the extensive national and international housing research and literature; and spatial, feasibility, portfolio, financial and demographic modelling. Accompanying the extensive literature and quantitative analysis was 
a lengthy qualitative engagement that included the establishment of a Ministerial Affordable Housing Consultative Group with representatives across the housing continuum, a housing and homelessness summit, small focus groups and workshops, and surveys and submissions (EPSDD 2018, pp. 11-12). These extensive qualitative data were analysed by the Housing ACT team to produce an engagement report that, in many instances, aligned with the quantitative data, crystalised the problems and then pointed to possible interventions and strategies.

\section{Question 3: What should we do?}

Using this evidence base, we developed three options papers addressing each of the challenges: context and challenges, our viability and funding, and growth and renewal. The papers outlined a broad range of options. These were judged using criteria similar to Moore's strategic triangle and, importantly, the quantitative and qualitative evidence fed into this process. These papers enabled busy decision-makers to quickly assess and consider possible solutions.

A critical part of the work was presenting the extensive evidence so that it was accurate and could be quickly understood. If you can say it in 30 pages, do not say it in 78 pages. If you can say it in one sentence, do not say it in three sentences. If you can say it in a picture, do. We included Figure 11.4 in our work. Even though the public housing business model is described every year in a plethora of annual report pages, it is largely and greatly misunderstood. This picture, which tells the story at a glance, has resulted in a new understanding of how public housing works and the incredible benefit that is provided to the most vulnerable people in our community.

The picture clearly shows the viability problem faced by all public entities in Australia (albeit using ACT data). What it also shows is the extent of public value that is delivered - that is, the investment in social inclusion and equity provided by the ACT Government on an annual basis (Scott $\&$ Baehler 2010). Financial statements do not do this. The story of public housing had not previously been presented to decision-makers in this way. It is the responsibility of 'policy wonks' to wrestle with the problem, evidence and options and present them in such a way that decision-makers have what they need. Pictures and diagrams that are designed with clean intent and based on evidence are a powerful tool to that end. 


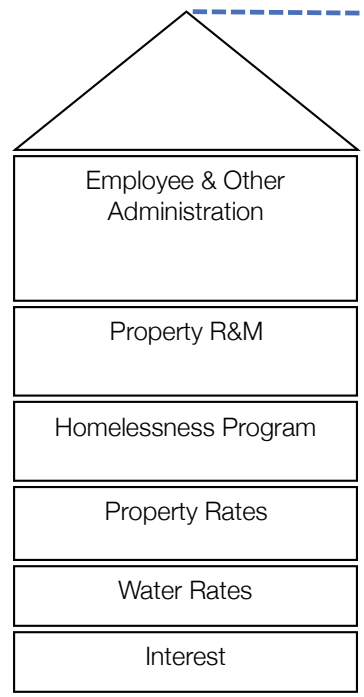

Expenditure

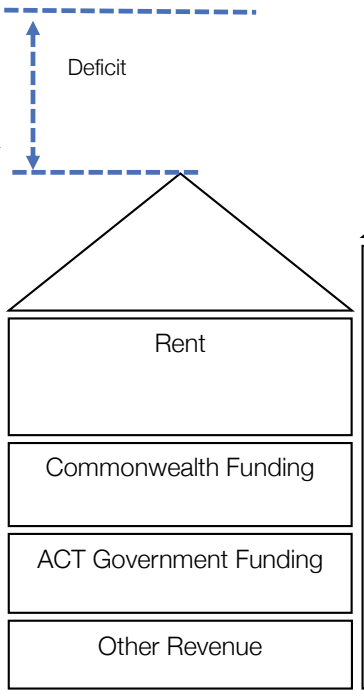

Revenue

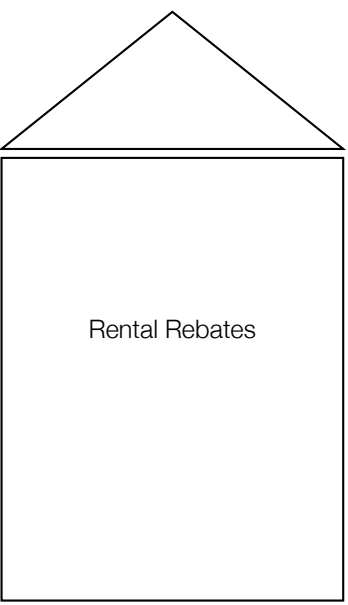

Social Investment

Figure 11.4. Visualisation of balance sheet data and social investment. ${ }^{3}$

The result is that the ACT Government is now investing $\$ 100$ million to grow public housing in the ACT. I would posit that public housing is not broken when approached and funded as social infrastructure.

\section{Question 4: What does success look like?}

There are many benefits that will be realised from the implementation of the Growing and renewing public housing 2019-2024 plan (Housing ACT 2019). These will be articulated against the wellbeing indicators and examined in a benefits realisation plan. In short, this plan will deliver 1,000 renewed properties and grow the portfolio by 200 properties to be dispersed throughout Canberra's suburbs and town centres. Our objective is to deliver homes that better match tenants' needs and provide a range of housing options. 'Having the right mix of social infrastructure means we are better equipped to provide vulnerable members of our community with the housing stability we need' (Housing ACT 2019).

3 I would like to acknowledge my South Australian housing colleague, Phil Fagan-Schmidt, who shared a similar diagram and sparked my thinking to adapt it and add the third 'house'. 


\section{Conclusion}

I keep those four questions and triangle at the top of my mind. I find it a useful framework to draw on when I have 90 seconds to brief a minister or when I have three years to deliver a strategy. It is scalable across problems, timeframes and resources. It allows for integration with other models, frameworks and approaches while providing a true north to fall back on when immersed in complexity.

\section{References}

ACT Environment, Planning and Sustainable Development Directorate (EPSDD) 2018, ACT housing strategy, ACT Government, Canberra.

ACT Government 2012a, Triple bottom line assessment for the ACT Government, viewed 19 January 2020, www.cmtedd.act.gov.au/_data/assets/pdf_file/0020/ 331373/TBL_Assessment_Framework.pdf.

ACT Government 2012b, Growth, diversification and jobs: A business development strategy for the $A C T$, viewed 19 January 2020, www.business.act.gov.au/_ data/assets/pdf_file/0017/430424/Business_Development_Strategy.pdf.

Alford, J \& O'Flynn, J 2009, 'Making sense of public value: Concepts, critiques and emergent meanings', International Journal of Public Administration, vol. 32, nos 3-4, pp. 171-91, doi.org/10.1080/01900690902732731.

Burgess, K 2019, 'ACT government to introduce wellbeing index', Canberra Times, 16 January, viewed 20 January 2020, www.canberratimes.com.au/story/ 5997331/act-government-to-introduce-wellbeing-index/.

Cunningham, G 1963, 'Policy and Practice', Public Administration, vol. 41, no. 3, pp. 229-38, doi.org/10.1111/j.1467-9299.1963.tb01786.x.

De Rassenfosse, GJ 2011, Understanding innovation: The role of policy intervention, a report for the Victorian Department of Treasury and Finance, Melbourne Institute of Applied Economic and Social Research: Intellectual Property Research Institute of Australia, Melbourne, Vic.

Freiberg, A 2010, The tools of regulation, The Federation Press, Sydney, NSW.

Gilding, L 2018, 'Practical realities of policy on the run', ANZSOG: Building communities of practice: Exploring how practitioners access and respond to academic policy frameworks, ANZSOG, Canberra, ACT. 
Goalcast 2017, 'Top 30 most inspiring Albert Einstein quotes of all times', viewed 19 January 2020, www.goalcast.com/2017/03/29/top-30-most-inspiringalbert-einstein-quotes/.

Housing ACT 2019, ACT housing strategy: Growing and renewing public housing 2019-2024, ACT Government, Canberra.

Moore, M 1995, Creating public value: Strategic management in government, Harvard University Press, Cambridge, MA.

Nutley, SW 2009, 'Past, present and possible futures for evidence-based policy', in G Argyrous, Evidence for policy and decision-making: A practical guide, UNSW Press, Sydney, NSW.

Productivity Commission 2017, Introducing competition and informed user choice into human services: Reforms to human services, Report no. 85, Commonwealth of Australia, Canberra, ACT.

Scott, C \& Baehler, K 2010, Adding value to policy analysis and advice, UNSW Press, Sydney, NSW.

Sparrow, M 2000, The regulatory craft: Controlling risks, solving problems \& managing compliance, Brookings Press, Washington, DC.

Westcott, B 2015, 'Minister bypassed officials advice', Canberra Times, 2 April, pp. 1,5 . 
This text is taken from Learning Policy, Doing Policy: Interactions Between Public Policy Theory, Practice and Teaching, edited by Trish Mercer, Russell Ayres, Brian Head and John Wanna, published 2021 by ANU Press, The Australian National University, Canberra, Australia.

doi.org/10.22459/LPDP.2021.11 